\title{
Reliability Assessment of a Main Propulsion Engine Fuel Oil System- What are the Failure-prone Components?
}

\author{
R. Islam \& M. Anantharaman \\ Australian Maritime College, University of Tasmania, Launceston, Australia \\ F. Khan \\ Memorial University of Newfoundland, St. John's, NL, Canada \\ V. Garaniya \\ Australian Maritime College, University of Tasmania, Launceston, Australia
}

\begin{abstract}
The main propulsion engine is the heart of a vessel which carries the entire load of the ship and propels to move ahead. The main engine consists of various sub-systems, the fuel oil system is the most important one. Fuel oil system provides fuel to the engine via a fuel injector mounted on the engine cylinder head. During the voyage, the main engine of a ship encounters a variation in loads and stresses due to rough weather to harsh manoeuvring, which sometimes leads to the breakdown of the main engine. Fuel oil systems are identified as one of the main reasons for engine breakdown. Many accidents happened due to the failure of the main engine fuel oil system in the last two decades. To ensure safe and reliable main propulsion engine operation, it is required to assess the reliability of a fuel oil system. However, there is a significant lack of appropriate data to develop the reliability assessment techniques for fuel oil system. This study proposes appropriate data collection and analysis procedure for the reliability assessment of a fuel oil system. Data related to Failure Running Hours (FRH) of a fuel oil system is collected from 101 experienced marine engineers through a questionnaire. The collected data processed using a box plot and analysed for a normality test. It helps to identify the generalization of the data. Moreover, this study identified failure-prone components of a fuel oil system. The collected data will help in developing reliability assessment techniques for accurate reliability analysis of a fuel oil system. The identified failure-prone components will assist in future reliability analysis and risk mitigation strategies for improving the overall safety and reliability of the shipping industry.
\end{abstract}

\section{INTRODUCTION}

In recent times, marine diesel engines used as the main propulsion source of a modern vessels. Marine diesel engine consists of various sub-systems, the fuel oil system is the most important one. However, many accidents happen due to the failure of a fuel oil system of the main propulsion engine (Islam et al., 2017a, Islam et al., 2016, Islam et al., 2018a). Inappropriate maintenance is one of the main causes for the failure of marine engines on-board. There is a lack of appropriate failure data that could help developing informed maintenance plan (Islam and $\mathrm{Yu}$, 2018). The engine manufacturers provide information for carrying out planned maintenance at specified running hours, without taking into consideration current condition. This study is focused on collecting relevant data from various sources to identify the most appropriate failure model representing a specific component of the engine. This study aims to use the structured questionnaire to collect the FRH data for the fuel oil system of the main propulsion engine. Moreover, this study identifies the failure-prone components. The collected data will be extremely valuable for developing the reliability assessment techniques and help to make a better maintenance plan of a fuel oil system of the main engine. The collected data and developed 
reliability assessment techniques will be very useful to assess the reliability of the marine engines and to plan the effective maintenance activities on-board the ship. As a result, this will help in improving the safety of marine engines.

This paper comprises five sections. Section 1 represents the introductory information about the study. Section 2 briefly presents the structure of the questionnaire and the selection of the respondents for conducting the survey. Section 3 presents a statistical analysis of the collected data. Section 4 presents the main finding of the study while Section 5 presents the conclusions.

\section{QUESTIONNAIRE STRUCTURE AND RESPONDENTS SELECTION}

The structure of the questionnaire discussed in this section to better understand the responses. The fuel oil system of the main propulsion engine consists of 13 components, a) Fuel Oil Suction Filter b) Fuel Oil Supply Pump c) Booster Pump d) Fuel Oil Main Discharge Filter e) Fuel Oil Bypass Filter f) Fuel Oil Heater g) Viscotherm h) Fuel Oil Injection Pump i) Fuel Oil Injector j) Fuel Oil High Pressure Pipe k) Buffer Tank l) Service Tank m) Flow Meter. These components play an important role to operate the fuel oil system effectively. The reliability of a fuel oil system is a product of all the 13 components. The structure of the questionnaire presented in Figure 1.

The structured questionnaire used, and an openended question asked from the respondents. The developed questionnaire is presented in Table 1.

There are two questions in the questionnaire, question 1 seeks a response to identify the type of engine and its model. Moreover, question 2 to pursues to know the FRH of each component of the fuel oil system of the main propulsion engine.
To collect the responses many marine engineers identified from the marine industry. The potential respondents selected based on their experience onboard ship as a marine maintenance engineer. Particularly, chief, a second and third engineer with at least 3 years of maintenance experience on-board ships are selected as a respondent. As they are the best person to ask the question who has the real-life experienced on-board. Moreover, these respondents have the experience to work in various type of ship (i.e. oil tanker, container ship, passenger ships, ferry etc). Furthermore, the respondents have an experience conducting maintenance activities in several types of marine diesel engines (i.e. two stroke, four stroke, high speed, medium speed, low speed etc.

The questionnaire sends to 200 experienced marine engineers around the world through e-mail. However, 101 responses received from the respondents. Based on the statistical validation by Islam et al. (2017a), (Islam et al., 2018a, Islam and Yu, 2018, Islam et al., 2018b) about 96 sample size is required to justify the accuracy of the collected responses. Therefore, the collected responses from 101 experienced marine engineers confirm the validity of enough responses for this study.

\section{STATISTICAL ANALYSIS OF THE RESPONSES}

Statistical analysis is required to process the collected data to develop the methodology for the reliability assessment techniques. Moreover, it is also required to identify the generalization of the collected data. Therefore, after collecting the responses, a box plot was drawn to eliminate the out layers of the FRH data for all 13 components of a fuel oil system. Figure 2 a) represents the box plot for the fuel oil suction filter of the main engine fuel oil system. The out layers eliminate considering a 95\% confidence interval for all the components.

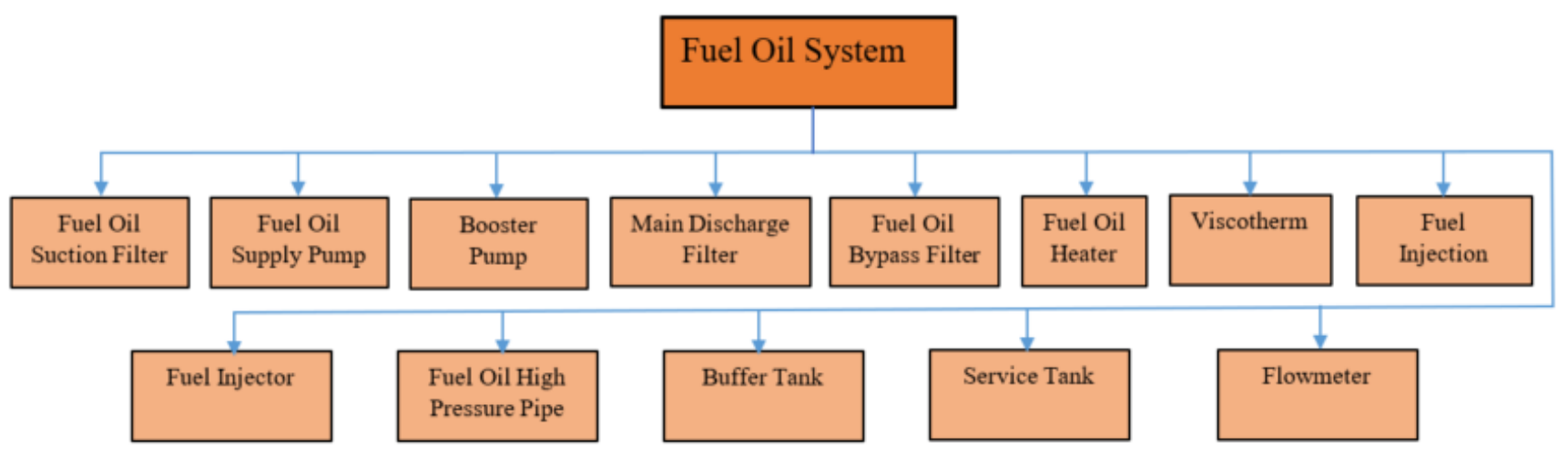

Figure 1. Structure of the Questionnaire 
Table 1. Questionnaire to collect the FRH data

\begin{tabular}{|c|}
\hline i) Please write the name of the engine and model number you are working with (e.g. MAN B\&W 6SMC60). \\
\hline Please provide Failure Running Hours (FRH) for the components of a main engine fuel oil system. For example, if the Planned Maintenance \\
Hours (PMH) is 500 and the component fails 100 hrs before PMH, it means (FRH) for the component is 400. Please note FRH < PMH.
\end{tabular}

a)
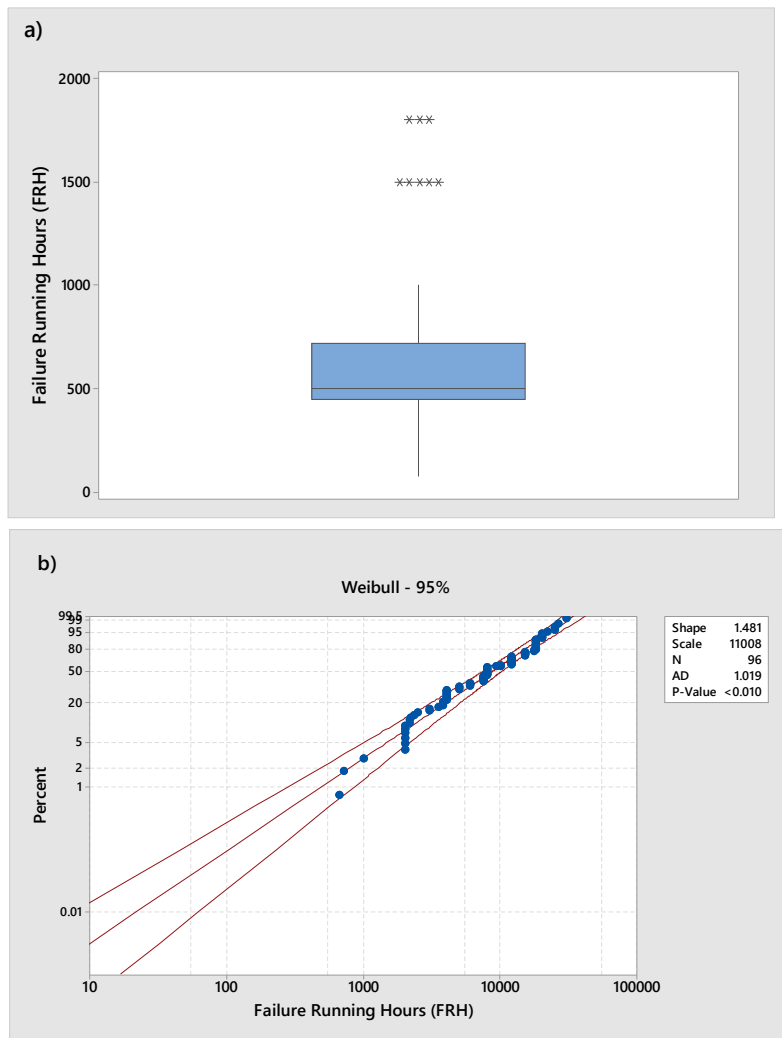

Figure 2: a) Box plot for Fuel oil suction filter and b) Weibull plot for fuel oil supply pump

Figure 2 b) represents the Weibull plot of a fuel oil suction filter. The Weibull plots were drawn for all the components for a fuel oil system. The plot clearly shows that most of the collected data doesn't follow the normal distribution nor Weibull considering a $95 \%$ confidence interval. As the "P" value is less than the 0.05 .

\section{RESULTS}

The results of this study presented in Figure 3 and Figure 4. The FRH data presented in Figure 3. It is very difficult to present a large number of data in typical graph plot which may look clumsy. Therefore, FRH data presented in a Frequency plot rather using a typical graph plot for better presentation. The collected FRH data for all the components of the main engine fuel oil system presented in Figure 3. These data can be used directly to develop reliability assessment techniques for the fuel oil system.

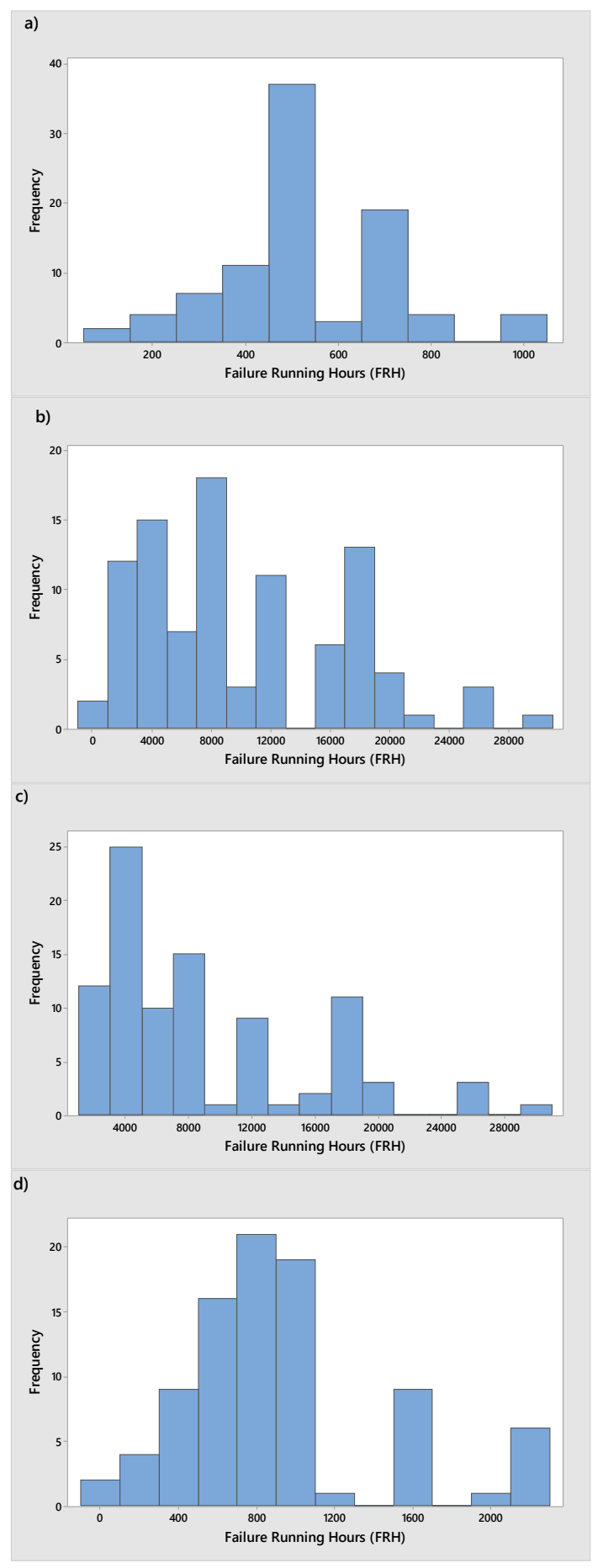



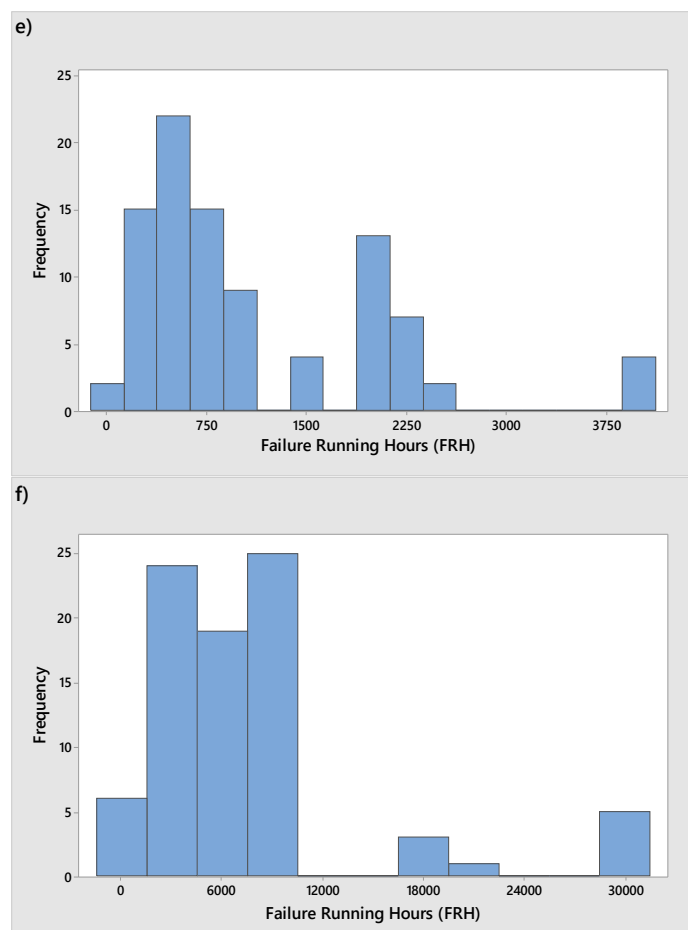

g)

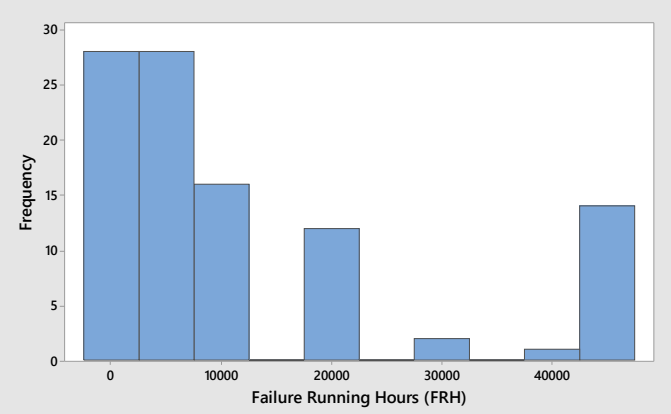

h)

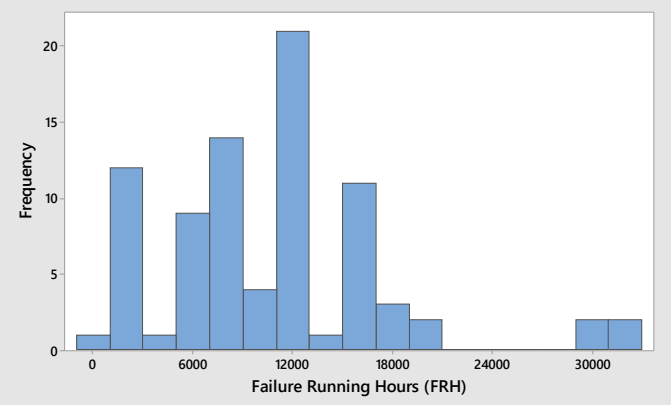

i)

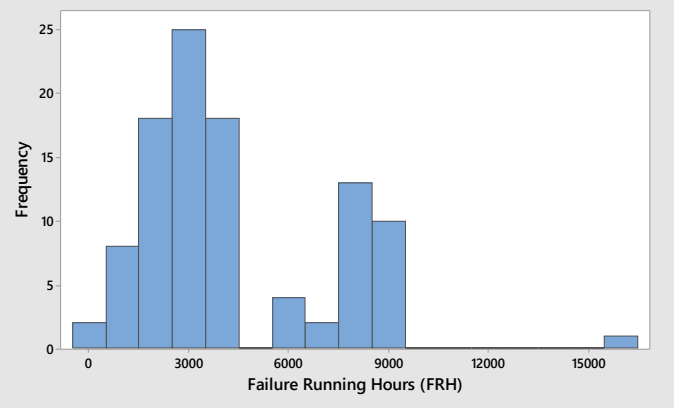

j)

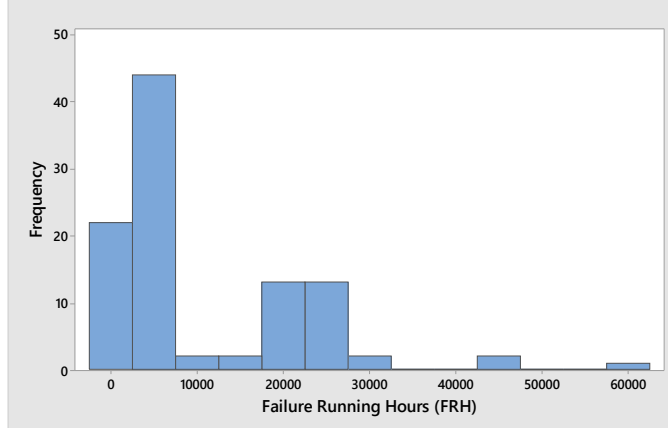

k)
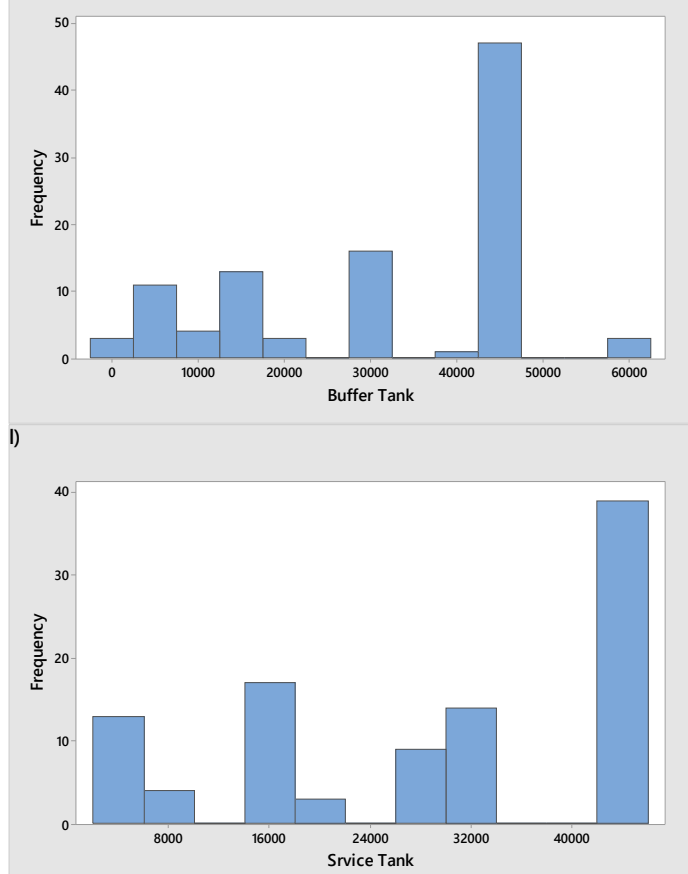

m)

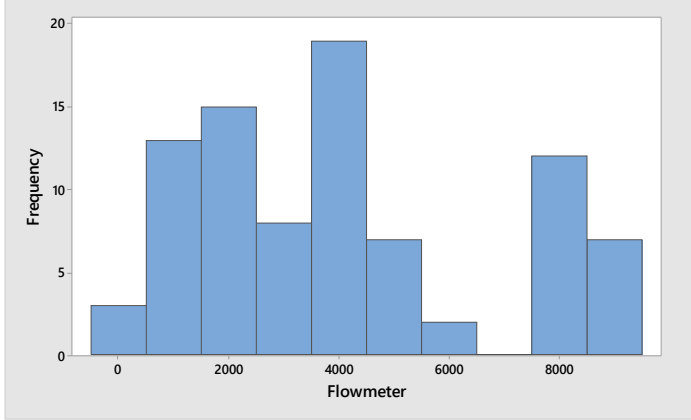

Figure 3. Frequency plot of Fuel Oil System: a) Fuel Oil Suction Filter, b) Fuel Oil Supply Pump, (c) Booster Pump, (d) Fuel Oil Main Discharge Filter, (e) Fuel Oil Bypass Filter, (f) Fuel Oil Heater, g) Viscotherm, h) Fuel Oil Injection Pump, i) Fuel Oil Injector, j) Fuel Oil High PressurePipe, k) Buffer Tank, 1) Service Tank, m) Flow Meter.

Figure 4 illustrates the mean, median and standard deviation of FRH for all the components of a fuel oil system. 


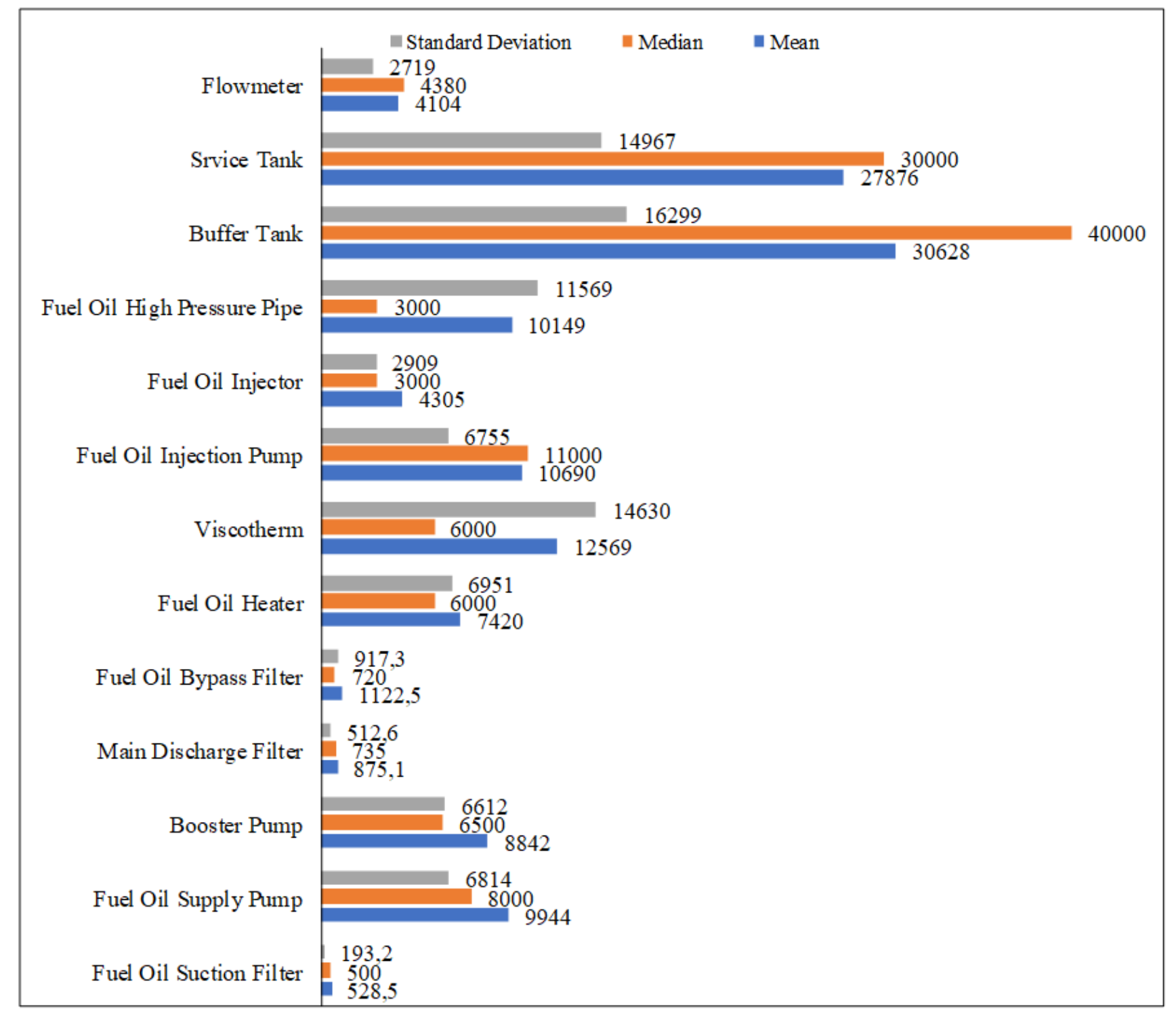

Figure 4. Mean, Median and Standard Deviation of FRH for a Fuel Oil System

The results of this study identify FRH for fuel oil filters is lower than other components of the system. It is preferable to have higher FRH for all the components of a fuel oil system, which leads to higher system reliability and vice versa. However, this study indicates fuel oil filters are relatively less reliable compared to other components of the system. Due to the maintenance of the filters is a very critical aspect of the fuel oil system, (Knowles and Baglee, 2012). Previous studies by Islam et al. (2016), Islam et al. (2017b) also found similar results earlier. Moreover, FRH for fuel oil supply pumps, fuel oil booster pumps, viscotherm, fuel oil heater, fuel injection pump, and fuel injectors are relatively moderate. Furthermore, FRH for fuel oil service tank and buffer tanks are high. However, fuel oil service tank and a buffer tank are the most reliable components of the system. Fuel oil service tank and buffer tank is a part of the fuel oil system. However, they are static components and not subject to any dynamic load. Therefore, they require minimum maintenance. Hence, they have higher FRH.

\section{CONCLUSIONS}

This study provides useful FRH data for the fuel oil system of the main propulsion engine. The collected data is unique in this field of study. These data enable generalization and the will help to develop reliability analysis techniques. The results of this study indicate, not all the data for a component of a main propulsion engines' fuel oil systems follow the same behaviour. The study identified fuel oil filters as a most failureprone components and fuel oil service tank and buffer tank as a lowest failure prone component. Based on the results of this study maintenance task of the fuel oil filters can prioritize which will help to increase the reliability of fuel oil filters. Moreover, it is required to give consideration for installation of an additional fuel oil filter which could be useful in rough weather condition. Interns, it will enhance the reliability of the fuel oil system of the main propulsion engine.

\section{REFERENCES}

ISLAM, R., ABBASSI, R., GARANIYA, V. \& KHAN, F. 2017a. Development of a human reliability assessment 
technique for the maintenance procedures of marine and offshore operations. Journal of Loss Prevention in the Process Industries, 50, 416-428.

ISLAM, R., ABBASSI, R., GARANIYA, V. \& KHAN, F. I. 2016. Determination of human error probabilities for the maintenance operations of marine engines. Journal of Ship Production and Design, 32, 226-234.

ISLAM, R., KHAN, F., ABBASSI, R. \& GARANIYA, V. 2018a. Human error assessment during maintenance operations of marine systems-What are the effective environmental factors? Safety science, 107, 85-98.

ISLAM, R., KHAN, F., ABBASSI, R. \& GARANIYA, V. 2018b. Human error probability assessment during maintenance activities of marine systems. Safety and health at work, 9, 42-52.
ISLAM, R. \& YU, H. 2018. Human Factors in Marine and Offshore Systems. Methods in Chemical Process Safety. Elsevier.

ISLAM, R., YU, H., ABBASSI, R., GARANIYA, V. \& KHAN, F. 2017b. Development of a monograph for human error likelihood assessment in marine operations. Safety science, 91, 33-39.

KNOWLES, M. \& BAGLEE, D. Condition management of marine lube oil and the role of intelligent sensor systems in diagnostics. 25th International Congress on Condition Monitoring and Diagnostic Engineering, COMADEM 2012, June 18, 2012 - June 20, 2012, 2012 Huddersfield, United Kingdom. Institute of Physics Publishing. 